\title{
Reduced levels of alpha-1-antitrypsin in cerebrospinal fluid of amyotrophic lateral sclerosis patients: a novel approach for a potential treatment
}

\author{
Uri Wormser ${ }^{1,6^{*}}$, Jessica Mandrioli ${ }^{2}$, Marco Vinceti ${ }^{3}$, Nicola Fini ${ }^{2}$, Amnon Sintov $^{4}$, Berta Brodsky ${ }^{1}$, \\ Elena Proskura ${ }^{1}$ and Yoram Finkelstein ${ }^{5}$
}

\begin{abstract}
Background: Amyotrophic lateral sclerosis (ALS) is an incurable neurodegenerative motor neuron disease that involves activation of the immune system and inflammatory response in the nervous system. Reduced level of the immuno-modulatory and anti-inflammatory protein alpha-1-antitrypsin (AAT) is associated with inflammation-related pathologies. The objective of the present is to determine AAT levels and IL-23 in the cerebrospinal fluid (CSF) of ALS patients and control group.

Findings: CSF samples from newly diagnosed ALS patients and age-matched controls were analyzed for AAT and IL-23 by ELISA and magnetic luminex screening, respectively. A statistically significant reduction of $45 \%$ in mean AAT levels was observed in the CSF of ALS patients $(21.4 \mu \mathrm{g} / \mathrm{ml}$ ) as compared to the control group (mean $38.8 \mathrm{\mu g} / \mathrm{ml}$, $p=0.013$ ). A statistically significant increase of $30.8 \%$ in CSF mean levels of the pro-inflammatory cytokine IL-23 was observed in ALS patients $(1647 \mathrm{pg} / \mathrm{ml})$ in comparison to the controls $(1259 \mathrm{pg} / \mathrm{ml}, p=0.012)$. A negative correlation coefficient $(r=-0.543)$ was obtained by linear regression analysis of the two measured parameters $(p=0.036)$.
\end{abstract}

Conclusions: Reduced AAT and elevated IL-23 CSF levels support the notion of neuroinflammatory process occurring in ALS patients. Increasing AAT levels in the patients' nervous system should be further investigated as a new therapeutic approach and a novel potential tool for ALS treatment.

Keywords: Antitrypsin, Amyotrophic lateral sclerosis, Motor neuron disease, Cerebrospinal fluid, ALS, MND

\section{Findings}

\section{Background}

Amyotrophic lateral sclerosis (ALS) is an incurable, neurodegenerative motor neuron disease with devastating impact that relentlessly causes injury and death of the lower motor neurons in the brainstem and spinal cord and of the upper motor neurons in the motor cortex [1]. Patients experience signs and symptoms of progressive muscle atrophy and weakness, fatigue and dysphagia, and typically succumb to respiratory failure $[2,3]$. The

\footnotetext{
* Correspondence: wormser@cc.huji.ac.il

${ }^{1}$ Institute of Drug Research, School of Pharmacy, Faculty of Medicine, The Hebrew University, POB 1206591120 Jerusalem, Israel

${ }^{6}$ David R. Bloom Center for Pharmacy at the Hebrew University and, The Dr. Adolf and Klara Brettler Centre for Research in Molecular Pharmacology and Therapeutics at the Hebrew University, Jerusalem, Israel

Full list of author information is available at the end of the article
}

median survival period from the clinical onset to the fatal outcome ranges from 20 to 48 months. However, a relatively small group (10-20\%) of the patients survives more than 10 years [4]. ALS is most commonly a sporadic disease while $10-15 \%$ of cases are familial [5]. The worldwide incidence of ALS is approximately 2-3 per 100,000 individuals [1], except for a few high-incidence foci, such as the Kii Peninsula and Guam [6].

Accumulating data support the notion that inflammatory processes are involved in ALS pathophysiology. Activation of microglia and astrocytes was demonstrated in both animal model and humans. Brain infiltration of both $\mathrm{CD}^{+}$and $\mathrm{CD}^{+} \mathrm{T}$ lymphocytes was shown in ALS patients [7]. Regulatory T lymphocytes number was found to be a prognostic factor both in animal models of ALS and in human patients affected by the disease [8]. Alterations 
in pro- and anti-inflammatory cytokines and growth factors such as IL-6, IL-10, GM-CSF, G-CSF, IL-2, IL-4, IL-8, IL12, IL-15, IL-17, IL-18, basic FGF, VEGF, and IFN-gamma were observed in CSF of ALS patients [9-12].

Apart from cytokines and growth factors, proteinase inhibitors play a central role in controlling inflammation. For instance, the serine proteinase inhibitor (serpin) alpha-1-antitrypsin (AAT) blocks neutrophil elastase and prevents pathological tissue disruption. Thus, its absence may lead to certain lung pathologies such as pulmonary emphysema, cystic fibrosis, and chronic obstructive lung disease [13]. In addition, the immuno-modulatory activities of AAT is expressed by controlling proinflammatory cytokine release [14], binding to complement C3 [15] and neutrophil functions [16]. Due to its anti-inflammatory properties, AAT is a drug candidate for various disorders including panniculitis, diabetes mellitus, rheumatoid arthritis, vasculitis, and fibromyalgia [13]. In view of the key function of AAT in controlling immunological response and inflammation, this study was aimed to quantitatively determine the levels of this protein and for comparing the pro-inflammatory cytokine IL-23, in CSF specimens of ALS patients and control group.

\section{Subjects and methods \\ Study participants}

ALS patients were recruited from a case series of residents of the Emilia-Romagna region, northern Italy. They were diagnosed with definite or probable ALS (revised El Escorial criteria) at the ALS Center of the Modena University Neurological Department from 2001 to 2011, and underwent lumbar puncture due to diagnostic procedures. This group included 58 consecutive patients with sporadic ALS; only 15 of them had at least $1 \mathrm{ml}$ CSF available for the present study. The 15 patients ( 10 males, 5 females) had at onset a mean age of 52 years (range 31-62 years); 13 patients presented with spinal onset and 2 with bulbar onset ALS. No patient presented with ALS-associated dementia or extrapyramidal signs. Distributions of phenotypes were as follows: 8 classic, 3 flail, 2 bulbar, and 2 upper motor neuron predominant phenotype. Mean disease duration from onset to death or last observation was 67 months. All the patients started Riluzole treatment after CSF sample withdrawal. Ten of them underwent genetic screening including all the major genes that are implicated in ALS (SOD1, C9ORF72, FUS, TDP43) with none testing positive. Genetic analysis could not be performed in the remaining patients due to lack of available blood samples.

The control population consisted of residents in the Emilia-Romagna region who were admitted to the same department between 2001 and 2011, and underwent lumbar puncture because of suspected but later on unconfirmed neurological disease. The signs and symptoms that led to neurological examination and lumbar puncture were mainly headache and paresthesia. Fourteen of these subjects were randomly selected and age matched ( \pm 10 yrs $)$ 1:1 to ALS patients. The 14 age-matched controls had a mean age of 54 years (range $32-71$ years). All the control patients were subsequently discharged from hospital without a diagnosis of a major disease.

Informed consent for diagnostic lumbar puncture (LP) was obtained from all the patients, and utilization of the CSF specimens for the present study was approved by the Modena Ethical Committee.

\section{Sample collection}

Approx. 6-8 mL of CSF were collected by LP from each patient and immediately stored at $-80{ }^{\circ} \mathrm{C}$ until in polypropylene tubes. A $1 \mathrm{ml}$ aliquot was transported by air courier, deep frozen in dry ice to the Institute of Drug Research (U. W.'s laboratory) at the Hebrew University of Jerusalem, and kept continuously frozen until use.

\section{Determination of AAT and IL-23}

AAT was determined (monoplicate) by ELISA kit validated for CSF (Assaypro, St. Charles, MO, USA, Cat No. EA5101-1) and cytokines by Human Magnetic Luminex screening assay (R\&D Systems, Minneapolis, MN, USA).

\section{Data analysis}

Statistical significance of the difference between the ALS and control groups was calculated by Student's $t$ test. Correlation coefficient of AAT and IL-23 data in ALS patients was calculated by Pearson's analysis.

\section{Results and discussion}

The present study demonstrates a statistically significant reduction of $45 \%$ in AAT mean CSF levels in ALS patients $(21.4 \mu \mathrm{g} / \mathrm{ml})$ as compared to the control group (mean $38.8 \mu \mathrm{g} / \mathrm{ml}, p=0.014$ ) (Fig. 1a, Table 1). The median values showed even greater reduction of $53 \%$ in AAT levels in the patients $(18 \mu \mathrm{g} / \mathrm{ml})$ in comparison to the controls $(38 \mu \mathrm{g} / \mathrm{ml})$ (Table 1$)$. These values are comparable to those previously found in human CSF by other laboratories [17-19]. In line with these findings, a statistically significant increase of $30.8 \%$ in CSF mean levels of the pro-inflammatory cytokine IL-23 was observed in ALS patients $(1647 \mathrm{pg} / \mathrm{ml})$ in comparison to the controls (1259 pg/ml, $p=0.012$ ) (Fig. 1b, Table 1). The median value showed $36 \%$ increase in the patients group (1678 pg/ml) as compared to the controls (1229 pg/ml) (Table 1). No statistically significant differences between both groups were detected for the other cytokines (IL-8, MCP-1, IL-17A, growth-related oncogene-alpha, unpublished data). As expected, a negative correlation coefficient $(r=-0.544)$ was obtained by linear regression analysis of the two measured parameters in ALS patients $(p=0.036)$ 


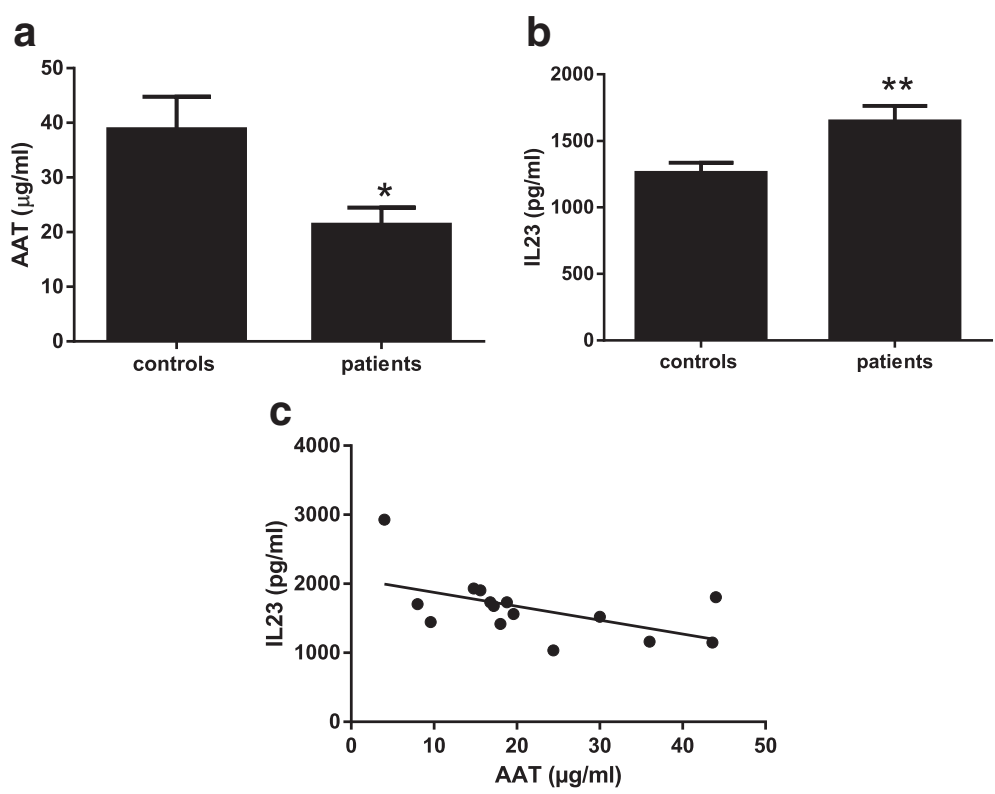

Fig. 1 AAT and IL-23 levels in CSF of ALS patients and controls. CSF specimens of patients and controls were determined for AAT (a) and IL-23 (b) by ELISA kit and Human Magnetic Luminex screening assay, respectively. Results are expressed as mean \pm SEM using Student's $t$ test for calculating the statistical significance of the difference between the two tested groups. $N=15$ for both AAT and IL-23 in ALS group while in the controls $n=14$ for AAT and $n=13$ for IL-23 determinations. ${ }^{*} p=0.014,{ }^{* *} p=0.012 ; \mathbf{c}$ Linear regression (Pearson test) of AAT and IL-23 in ALS patients. $R=-0.544 ; p=0.036$

(Fig. 1c). No linear correlation was observed between AAT and IL-23 in the control group $(r=0.065)$ (linear regression data not shown).

To our best knowledge, this is the first report on a significant reduction of AAT levels in CSF of ALS patients. The lack of this anti-inflammatory and immune-modulatory protein is inversely correlated with the increase of the proinflammatory cytokine IL-23 in the patients. These findings are compatible with the accumulating evidence for the link between ALS and inflammation [7, 20] expressed by alterations in levels of cytokines and growth factors [9, 10, 21].

Brettschneider and colleagues through proteomic analysis identified two proteins that were upregulated (alpha1-antitrypsin precursor and Zn-alpha-2-glycoprotein) and three proteins (ceruloplasmin precursor, transferrin, and beta-2-microglobulin) that were downregulated in the
CSF of ALS patients [22]. Elevation of AAT precursor and reduction in AAT levels may stem from inappropriate conversion of the precursor to its final product leading to decrease in AAT levels in CSF of ALS patients. Another study identified serine proteases and serpins (alpha-1-antitrypsin, alpha-1-anti-chymotrypsin, and protease nexin I) in motoneurons in neurofilament conglomerates suggesting that the imbalance of serine proteases and internalized serpins may play a role in the pathogenesis of ALS [23].

Whether altered AAT levels are a result of the pathological processes in the neuronal system or a factor involved in the evolution of the disease remains an open question. Nevertheless, the central role of AAT in controlling various inflammatory processes, and the variety of diseases associated with inappropriate levels of AAT may lead to the notion that lack of this protein may be

Table 1 Quantification of AAT and IL-23 in CSF of ALS patients and controls

\begin{tabular}{lllll}
\hline Tested parameter & Tested group & Mean \pm SEM & Change $^{\text {a }} \%$ & Median $^{\text {Change }}(\%)$ \\
\hline AAT & Control & $38.8 \pm 6.0 \mu \mathrm{mg} / \mathrm{ml}$ & & $38.0 \mu \mathrm{\mu g} / \mathrm{ml}$ \\
AAT & Patient & $21.4 \pm 3.1 \mu \mathrm{g} / \mathrm{ml}^{*}$ & -45 & $18.0 \mu \mathrm{\mu g} / \mathrm{ml}$ \\
IL-23 & Control & $1259 \mathrm{pg} / \mathrm{ml}$ & & $1229 \mathrm{pg} / \mathrm{ml}$ \\
IL-23 & Patient & $1647 \mathrm{pg} / \mathrm{ml}^{* *}$ & +30.8 & $1678 \mathrm{pg} / \mathrm{ml}$ \\
\hline
\end{tabular}

CSF specimens of patients and controls were determined for AAT and IL-23 by ELISA kit and Human Magnetic Luminex screening assay, respectively. Results are expressed as median or mean \pm SEM using Student's $t$ test for calculating the statistical significance of the difference between the two tested groups. $N=15$ for both AAT and IL-23 in ALS group while in the controls $n=14$ for AAT and $n=13$ for IL-23 determinations ${ }^{*} p=0.014,{ }^{* *} p=0.012$

${ }^{a}$ Expresses the percent of change (reduction or elevation) taking the control as $100 \%$ 
involved in the pathogenic process of ALS or in its clinical course. Should these results be confirmed in larger studies, increasing levels of this protein in the neuronal system of the patients may serve as a novel therapeutic approach for ALS. Replacement therapy by intravenous augmentation of AAT has been approved by the US-FDA for AAT deficiency such as in individuals with severe COPD or emphysema [24]. However, targeting the CNS is more convoluted and challenging and needs an alternative route of administration. As it is evident now that a direct pathway connects a submucosal compartment in the nasal passages to brain interstitial fluid, the nose-to-brain delivery of large molecular weight molecules can be feasible via intranasal administration. Thus, the central nervous system accessibility can be achieved by intranasal administration of a nanotechnology-based compounded protein [25], which may also be a convenient and efficient procedure for ALS patients.

\section{Abbreviations}

AAT, alpha-1-antitrypsin; ALS, amyotrophic lateral sclerosis; COPD, chronic obstructive pulmonary disorder; CSF, cerebrospinal fluid; IL-23, interleukin-23

\section{Authors' contributions}

UW contributed to the study design and concept, supervision of the study, and writing the manuscript. JM collected the CSF samples, contributed to the acquisition of the clinical data, contributed to the interpretation of data, and revised the manuscript. MV contributed to the coordination, analysis, and interpretation of data and revised the manuscript. NF contributed to the acquisition of the clinical data and interpretation of data. AS contributed to the study design and revised the manuscript. BB contributed to the study design, laboratory assays and analysis of data. EP contributed to data acquisition and analysis. YF contributed to the study concept and design, and writing the manuscript. All authors read and approved the final manuscript.

\section{Competing interests}

The authors declare that they have no competing interests.

\section{Author details}

${ }^{1}$ Institute of Drug Research, School of Pharmacy, Faculty of Medicine, The Hebrew University, POB 1206591120 Jerusalem, Israel. ${ }^{2}$ Department of Neuroscience, S. Agostino- Estense Hospital, and University of Modena and Reggio Emilia, Modena, Italy. ${ }^{3}$ Research Centre for Environmental, Genetic and Nutritional Epidemiology (CREAGEN), University of Modena and Reggio Emilia, Modena, Italy. ${ }^{4}$ Department of Biomedical Engineering, Faculty of Engineering Sciences, Ben Gurion University of the Negev, Beer Sheva 84105, Israel. ${ }^{5}$ Service and Unit of Neurology and Toxicology, Shaare Zedek Medical Center, Jerusalem, Israel. ' David R. Bloom Center for Pharmacy at the Hebrew University and, The Dr. Adolf and Klara Brettler Centre for Research in Molecular Pharmacology and Therapeutics at the Hebrew University, Jerusalem, Israel.

\section{Received: 5 April 2016 Accepted: 19 May 2016}

Published online: 01 June 2016

\section{References}

1. Chio A, Logroscino G, Traynor BJ, Collins J, Simeone JC, Goldstein LA, White LA. Global epidemiology of amyotrophic lateral sclerosis: a systematic review of the published literature. Neuroepidemiology. 2013;41:118-30.

2. Sejvar JJ, Holman RC, Bresee JS, Kochanek KD, Schonberger LB. Amyotrophic lateral sclerosis mortality in the United States, 1979-2001. Neuroepidemiology. 2005;25:144-52.

3. Kaltsakas G, Rentzos M, Alexakis T, Zouvelou V, Palamidas AF, Gennimata SA, Xirou S, Evdokimidis I, Koulouris NG. Upper airway dysfunction in amyotrophic lateral sclerosis. Eur Respir J. 2015;46(suppl):59.
4. Chio A, Logroscino G, Hardiman O, Swingler R, Mitchell D, Beghi E, Traynor BG. Prognostic factors in ALS: a critical review. Amyotrophic Lateral Scler. 2009;10:310-23.

5. Mehta P, Antao V, Kaye W, Sanchez M, Williamson D, Bryan L, Muravov O, Horton K. Prevalence of amyotrophic lateral sclerosis-United States, 2010-2011. MMWR Surveill Summ. 2014;63 Suppl 7:1-14.

6. Dombroski BA, Galasko DR, Mata IF. C9orf72 hexanucleotide repeat expansion and Guam amyotrophic lateral sclerosis-parkinsonism-dementia complex. JAMA Neurology. 2013;70:742-5.

7. Evans MC, Couch Y, Sibson N, Turner MR. Inflammation and neurovascular changes in amyotrophic lateral sclerosis. Mol Cell Neurosci. 2013;53:34-41.

8. Henkel JS, Beers DR, Wen S, Rivera AL, Toennis KM, Appel JE, Zhao W, Moore DH, Powell SZ, Appel SH. Regulatory T-lymphocytes mediate amyotrophic lateral sclerosis progression and survival. EMBO Mol Med. 2013;5:64-79.

9. Rentzos M, Rombos A, Nikolaou C, Zoga M, Zouvelou V, Dimitrakopoulos A, Alexakis T, Tsoutsou A, Samakovli A, Michalopoulou M, Evdokimidis J. Interleukin-17 and interleukin-23 are elevated in serum and cerebrospinal fluid of patients with ALS: a reflection of Th17 cells activation? Acta Neurol Scand. 2010;122:425-9.

10. Bonsi R, Fenoglio C, Serpente M, Cioffi SMG, Villa C, Ridolfi E, Barone C, Arighi A, Fumagalli GG, Ghezzi L, Mercurio M, Scarpini E, Galimberti D. Cytokine gene expression in peripheral cells from C9ORF72 mutation carriers with frontotemporal lobar degeneration. Clin Neuropathol. 2013:32:217-8.

11. Mitchell RM, Freeman WM, Randazzo WT, Stephens HE, Beard JL, Simmons Z, Connor JR. A CSF biomarker panel for identification of patients with amyotrophic lateral sclerosis. Neurology. 2009;72:14-9.

12. Rentzos M, Rombos A, Nikolaou C, Zoga M, Zouvelou V, Dimitrakopoulos A, Alexakis T, Tsoutsou A, Samakovli A, Michalopoulou M, Evdokimidis I. Interleukin-15 and Interleukin-12 are elevated in serum and cerebrospinal fluid of patients with amyotrophic lateral sclerosis. Eur Neurol. 2010;63:285-90.

13. Bergin D, Hurley K, McElvaney N, Reeves E. Alpha-1 antitrypsin: a potent anti-inflammatory and potential novel therapeutic agent. Arch Immunol Ther Exp. 2012;60:81-97.

14. Pott GB, Chan ED, Dinarello CA, Shapiro L. a-1-Antitrypsin is an endogenous inhibitor of proinflammatory cytokine production in whole blood. J Leukoc Biol. 2009;85:886-95.

15. O'Brien ME, McCarthy C, Henry M, Bergin DA, Meleady P, Reeves EP, Clynes M, McElvaney NG. Alpha-1 antitrypsin binds complement C3: a novel immune regulatory role. Ir J Med Sci. 2013;182:S440.

16. Hurley K, Bergin DA, Reeves EP, McElvaney NG. Alpha-1 antitrypsin augmentation therapy is associated with decreased neutrophil ADAM-17 activity, plasma TNF-(alpha) levels and normalisation of neutrophil apoptosis. Ir J Med Sci. 2012;181:S413-4.

17. Galvez S, Farcas A, Monari M. The concentration of alpha-1-antitrypsin in cerebrospinal fluid and serum in a series of 40 intracranial tumors. Clin Chim Acta. 1979;91:191-6.

18. Hoffman HDP, Donald PR, Hanekom C, De Beer F. Cerebrospinal fluid alpha-1-antitrypsin alpha-1-antitrypsin-elastase complex levels in meningitis. Eur J Clini Invest. 1989;19:26-9.

19. Nielsen HM, Minthon L, Londos E, Blennow K, Miranda E, Perez J, Crowther DC, Lomas DA, Janciauskiene SM. Plasma and CSF serpins in Alzheimer disease and dementia with Lewy bodies. Neurology. 2007;69:1569-79.

20. Hayashi S, Yamasaki R, Masaki K, Murai H, Okamoto K, Kira J-I. Morphological evidences of glial inflammation that confer spinal white matter degeneration of sporadic amyotrophic lateral sclerosis. Amyotrophic Lateral Scler Frontotemporal Degener. 2014;15:158-9.

21. Hensley K, Fedynyshyn J, Ferrell S, Floyd RA, Gordon B, Grammas P, Hamdheydari L, Mhatre M, Mou S, Pye QN, Stewart C, West M, West S, Williamson KS. Message and protein-level elevation of tumor necrosis factor (alpha) (TNF(alpha)) and TNF(alpha)-modulating cytokines in spinal cords of the G93A-SOD1 mouse model for amyotrophic lateral sclerosis. Neurobiol Dis. 2003;14:74-80.

22. Brettschneider J, Mogel H, Lehmensiek V, Ahlert T, Suessmuth S, Ludolph A, Tumani H. Proteome analysis of cerebrospinal fluid in amyotrophic lateral sclerosis (ALS). Neurochem Res. 2008;33:2358-63.

23. Chou SM, Taniguchi A, Wang S, Festoff BW. Serpin = serine protease-like complexes within neurofilament conglomerates of motoneurons in amyotrophic lateral sclerosis. J Neurol Sci. 1998;160(Supplement 1):S73-9. 
24. Alkins SA, O'Malley P. Should health-care systems pay for replacement therapy in patients with alpha(1)-antitrypsin deficiency? A critical review and cost-effectiveness analysis. Chest. 2000;117:875-80.

25. Botner B, Friedman A, Sintov AC. Direct delivery of intranasal insulin to the brain via microemulsion as a putative treatment of CNS functioning disorders. J Nanomed Nanotechnolo. 2012:3:136.

Submit your next manuscript to BioMed Central and we will help you at every step:

- We accept pre-submission inquiries

- Our selector tool helps you to find the most relevant journal

- We provide round the clock customer support

- Convenient online submission

- Thorough peer review

- Inclusion in PubMed and all major indexing services

- Maximum visibility for your research

Submit your manuscript at www.biomedcentral.com/submit 